\title{
Psychological Stressor Caused Alpha-Male Non-Human-Primate Macaca Fascicularis to Become Agonistic When Struggling Over Food
}

\author{
Rosyid Ridlo Al Hakim ${ }^{1,2}$; Erie Kolya Nasution ${ }^{1}$
}

\author{
Published online: 25 June 2021.
}

\begin{abstract}
Abstrak
Primates are the object of increased research recently. Experiments on non-human-primates (NHP) can determine their psychological level. NHP Macaca fascicularis is a primate that lives socially with a social hierarchy. Alpha-male becomes the leader of the group. Beneficial access is higher in alpha-male, against the conflicts to be initiated for certain interests. This study provides an overview of alpha-male aggressiveness in groups based on psychological stressors obtained during field observations. The research was conducted at Mbah Agung Karangbanar Religious Tourism Park, Central Java, Indonesia, group-size of 12 adult male, 14 adult female, 8 sub-adult male, 9 sub-adult female, 10 juvenile male, 14 juvenile female, and 6 infants. Aggressive observation (sampling-rules) is behavioral-animal sampling on alpha-male individuals and one individual for each age group as the subject of observation. Observations were carried out for 8 days with one-zero sampling. Adult male and alpha-male aggressive behavior ranked the highest during observation, that psychological stressors obtained.
\end{abstract}

Kata kunci: Agonistic, Aggressive Behavior, Macaca fascicularis, psychological stressor

\section{INTRODUCTION}

Primates have been the object of increasing research in recent times. Experiments on primates to determine their psychological level can include the use of tools, training in particular test situations such as problem-solving, "selfcontrol" studies, cognitive levels, and aggressive behavior (Sterling et al., 2013). Non-human primates (NHP) such as Macaca fascicularis are evolutionarily similar to humans, especially in certain psychological conditions that affect their behavior (Kappeler \& Schaik, 2006).

NHP Macaca fascicularis is a group of primates that live socially. The relationship between individuals makes group integrity possible. Like one male-male relationship, studies

\footnotetext{
${ }^{1}$ Faculty of Biology, Universitas Jenderal Soedirman; Jl. Dr. Soeparno 63 Purwokerto Central Java Indonesia, +62 281638-794

${ }^{2}$ Faculty of Information Sciences and Engineering, Jakarta Global University; Grand Depok City Jl. Boulevard Raya 2 Depok West Java Indonesia, +62 21-846-1155
}

\section{*) corresponding author}

Rosyid Ridlo Al Hakim

Email: rosyid.hakim@mhs.unsoed.ac.id according to Mishra et al. (2020), it is reported that there is competition for mating partners, monopolization of females, reciprocity among the males, strengthening the existence of relationships in groups, and related to social bonds.

Alpha-male is the group leader in the NHP, based on resource requirements, successful mating, and a higher level of aggressiveness than individuals with lower social strata. Alpha-male access in the group ranks highest, observations Al Hakim (2021), it was reported that the alpha-male aggressive rate was at a frequency of $4.79 \%$ compared to individuals in the lower social strata which was only $2.48 \%$.

This high level of aggression can be influenced by various factors, including personality or temperament (Al Hakim, 2021; Coleman, 2012; Freeman \& Gosling, 2010; Lutz \& Brown, 2018; Robinson et al., 2021; Weiss et al., 2011), hormones (de Waal \& Ferrari, 2012; Sterling et al., 2013), genetic (Dunbar, 1988), and psychological pressure by other individuals in the group (Kappeler \& Schaik, 2006). This study can provide an overview of alpha-male aggressiveness in groups based on psychological triggers that may be obtained during field observations.

\section{Theoretical Review}

Agonistic behavior was previously reported to be initiated by alpha males through conflict strategies, to fight against individuals in lower social strata. The frequency of 
aggression (agonism/agonistic) was reported in the alphamale $4.79 \%$ (Al Hakim, 2021), for adult male 3.18\%, adult female $2.78 \%$, sub-adult male $1.49 \%$, sub-adult female $0 \%$, juvenile male $1.49 \%$, juvenile female and infant $0 \%$ (Nasution \& Rukayah, 2018). As reported by Nugroho et al. (2021), Macaca fascicularis can be used as a comparative psychological model based on social behavior recorded during observation.

Reported aggressive behavior by Gygax (2000) occurs in high-ranking males. The aggressive interactions that are issued against the low-ranking males, are to avoid the aggressiveness that appears, and the victim due to aggressive actions will try to avoid and hide in a hiding place. According to Nugroho et al. (2021), one of the controlling factors for the aggressiveness of Macaca fascicularis, one of which is an environmental inhibitor and psychological stressor factors (de Waal \& Ferrari, 2012; Girard-Buttoz et al., 2014; Kappeler \& Schaik, 2006; Setchell \& Curtis, 2011; Sterling et al., 2013).

Psychology is a discipline that studies thoughts and behavior, including primate orders. Studies that include psychology are not limited to comparative psychology, ethology, and animal behavior. The behavior of animals and humans shows similar behavior, due to the evolutionary homology or analogy. The argument about analogy shows that the behavior of humans and other animals can be adapted to their surroundings. Genetically, anatomy, physiology, and cognition prove primates exhibit behavior that is not much different from humans, including nonhuman-primates (NHP) (Maestripieri, 2003).

The hypothesis of this study is based on theoretical studies, among others 1) alpha-male shows high aggressiveness compared to low-ranking social individuals; 2) psychological stressor factors prove the level of alphamale aggressiveness to be high compared to low-ranking social individuals. In addition, the novelty that this study offers, among others, proves alpha male has a different level of aggressiveness compared to individuals with different social hierarchies.

\section{METHOD}

\section{Subject and Behavior Observations}

A long-tailed monkey (Macaca fascicularis) as the leader of the group, otherwise known as alpha-male, and an individual representing his age whose habitat is in Mbah Agung Karangbanar Religious Tourism Park, Central Java, Indonesia. The Macaca fascicularis group size consists of 73 individuals, with 12 adult males, 14 adult females, 8 subadult males, 9 sub-adult females, 10 juvenile males, 14 juvenile females, and 6 infants. The focus of aggressive observation (sampling rules) is behavioral animal sampling on alpha-male individuals and one individual for each age group as the subject of observation (alpha-male, adult male, adult female, sub-adult male, sub-adult female, juvenile male, juvenile female, infant). Alpha-male was determined based on the bait-test method, by providing provisioning food to the Macaca fascicularis group (Al Hakim, 2021; Altmann, 1974; Simpson \& Simpson, 1977), carried out for 8 days from 08:00 to 17:00, with each recording time interval every 15 minutes, so that a total interval of 32 was obtained. Supporting data in the form of environmental factors were also recorded (Modified from Al Hakim, 2021).

\section{Aggressive Observations}

Subjects (alpha-male, adult male, adult female, subadult male, sub-adult female, juvenile male, juvenile female, infant) observed were aggressive behavior when fighting over food provided by visitors for 8 days of observation with video recording. done over and over. Based on the video recording (recording data rules), the aggressive behavior of fighting over food on the subject will be recorded as a quantitative value ( 0 did not do, 1 did). Aggressive data is recorded for 15 minutes based on video recording for each interval. All the aggressive data obtained were analyzed.

Aggressive behavior obeys Anderson \& Kinnally (2020) including threatening, biting, chasing, scratching, flattening (pressing into the ground), dragging, pushing away, or grabbing. Aggressive which is issued by individuals based on the presence of triggers (stressors) and psychologically has been tested before (de Waal \& Ferrari, 2012; Girard-Buttoz et al., 2014; Kappeler \& Schaik, 2006; Setchell \& Curtis, 2011; Sterling et al., 2013), and observed behavior is influenced by the psychological state of the individual (Bardi et al., 2017; Coleman, 2012; Dunbar, 1988; Hansen et al., 2021; Maestripieri, 2003; Nugroho et al., 2021; Veenema et al., 1997) because aggressive observation can only be observed not directly in contact with the subject (Setchell \& Curtis, 2011). In one aggression it was recorded since two individuals appeared (dyadic) with one of the individuals issuing threats in the form of voice or face-threatening until the other individual chose to yield or become a victim. Aggressive duration is very variable and tends to be very fast, so that to record one-time aggressive (agonistic) onezero sampling is recorded regardless of the recorded duration.

\section{Data Analysis}

All recorded aggressive quantitative data using onezero sampling were analyzed using ethogram diagrams. This is to provide an overview of each individual who is recorded as engaging in aggressiveness during the observation time.

\section{RESULT}

The results during the 8 days of observation showed that the total aggressive behavior issued by each individual was as much alpha-male 28 times, adult male 55 times, adult female 19 times, sub-adult male 21 times, sub-adult female 22 times, juvenile male 17 times, juvenile female 15 times, infant 0 times. The total aggressive distribution can be seen in Figure 1.

Figure 1 illustrates that the total aggression produced by adult-male individuals is higher than other individuals, including alpha males who are socially more dominant than other individual social strata, but in terms of age there is almost no difference in the age range of the adult-male male. Alpha-male and adult-male are more often seen fighting over food provided by visitors at Mbah Agung Karangbanar Religious Tourism Park. The total aggressiveness of each individual then calculated the total frequency of observations ( 8 days) to obtain an ethogram diagram of aggressive behavior. It can be seen in Figure 2 .

Based on Figure 2, the aggressive frequency is dominated by the adult-male group, followed by the alphamale, who are still in the same group age. The younger the age, the less aggressive activity, the infant did not find any aggressive actions during the observation. 


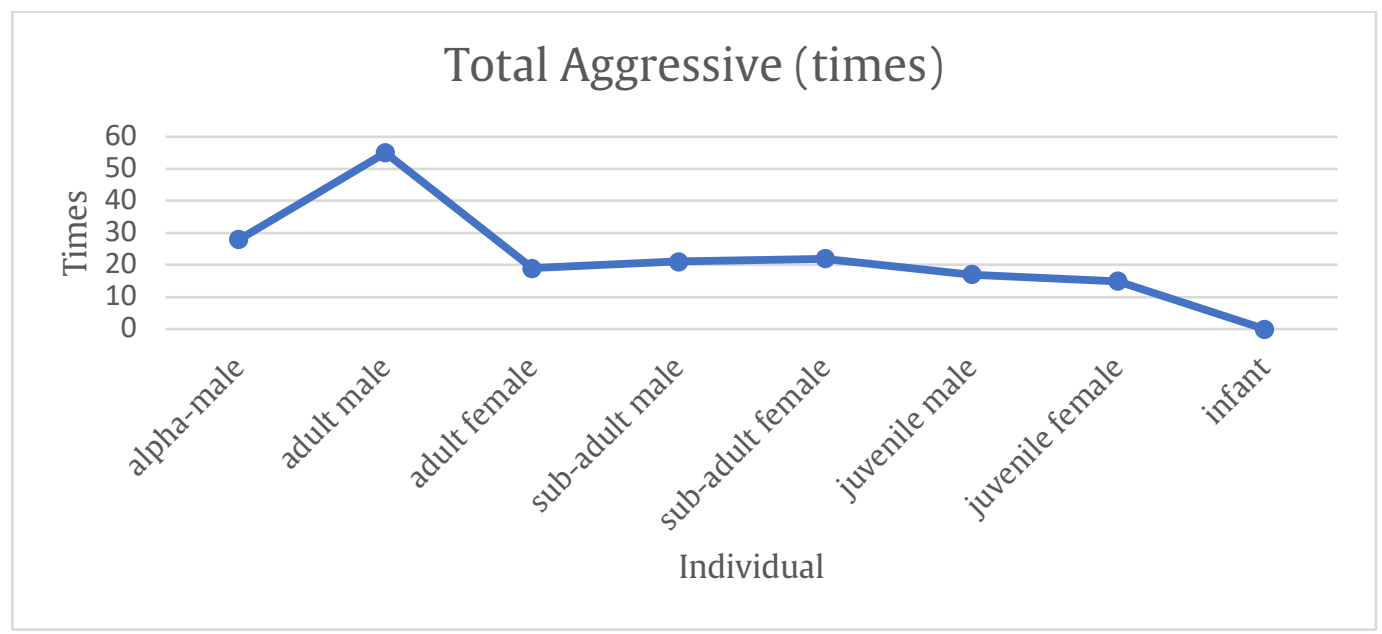

Figure 1. Total aggressive each individual (in times)

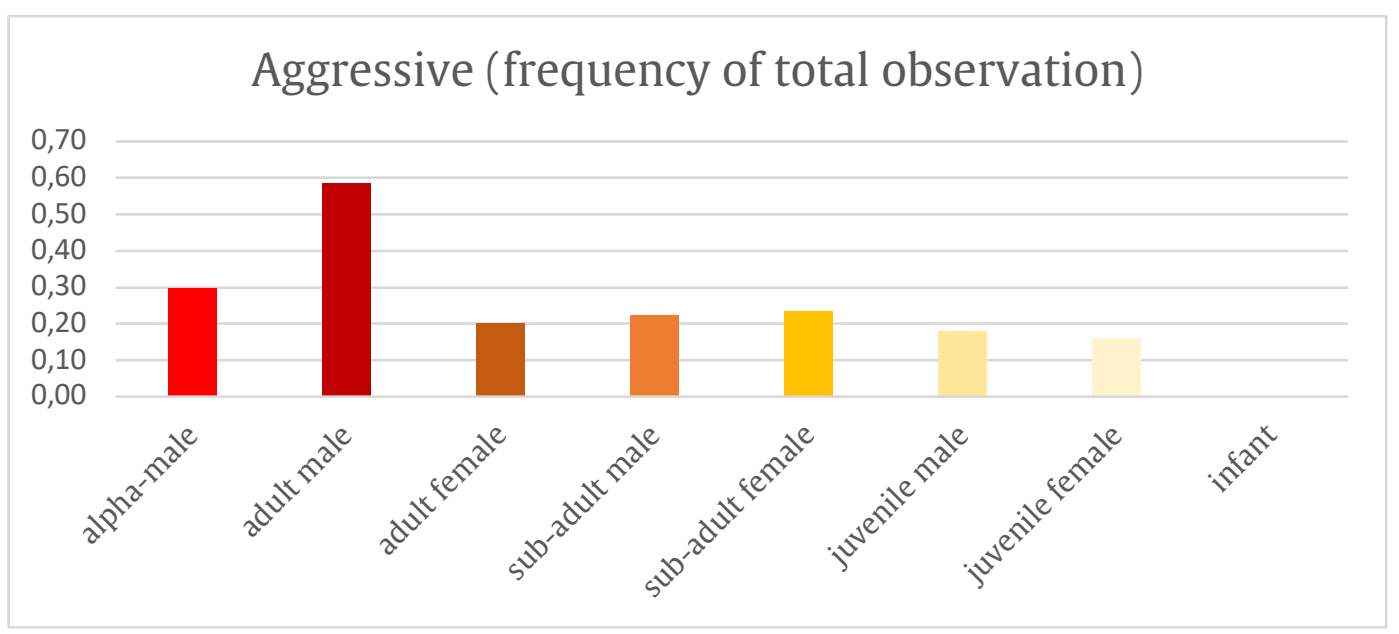

Figure 2. Frequency of total observation of aggressive each individual

\section{DISCUSSION}

Alpha-male provides higher intervention to threaten other individuals when fighting over food. Figure 3 is a threat issued by alpha-male to individuals with lower social strata, to win over food, alpha-male threatens in the form of voices and bluffing (Al Hakim, 2021).

The aggressive behavior of the long-tailed macaque (Macaca fascicularis) is influenced by psychological and hormonal factors (de Waal \& Ferrari, 2012; Sterling et al., 2013) as well as genetic (Dunbar, 1988), temperament, and personality (Coleman, 2012; Freeman \& Gosling, 2010; McCowan et al., 2011; Robinson et al., 2021; Weiss et al., 2011). Psychological factors play an important role in the behavior of each individual in dealing with the surrounding conditions. This factor is inherited based on the evolutionary line of their ancestors (Kappeler \& Schaik, 2006).

The emotional condition caused by an individual who is getting older is influenced by psychological attributes in the form of emotions. This has emerged since the existence of natural selection, with interactions between interacting individuals, giving rise to a complex of emotions, sympathy, liking, and wanting. Kappeler \& Schaik (2006) reported emotions this can occur because of: 1 ) fear of being cheated;
2) trust-distrust; 3) envy and jealousy. During the 8-day observation, the alpha-male was seen to show these three, especially during the process of fighting over-provisioning food from visitors. Alpha-male will not succumb to individual opponents in fighting over the food, in fact, not infrequently he will initiate conflict (Figure 3).

The initiation of this conflict is a form of communication work, to be able to create a social atmosphere and social dissemination, often with psychological stressors creating conflict-based communication, but this can benefit their groups, among others, to increase cooperation with one another (Kappeler \& Schaik, 2006). Some aggressive measures or psychological trauma give rise to reproductive suppression potentials (Dunbar, 1988).

Primatologists in observing his research subjects, will at least consider minimum contact with the subject and a psychological disturbance to interact with the subject, or by making traps. Primate thinking will influence how it creates aggressive actions for situations that according to it is threatening, this behavior can act as anti-predatory behavior, or fight over resources (Setchell \& Curtis, 2011) in a psychological state (there are psychological stressors) (Hansen et al., 2021). Alpha males exhibit this behavior for the same reason, as anti-predatory behavior towards individuals in lower social strata and fighting over food 
resources (Figure 3 ). In addition, aggressive behavior is also reported in terms of reproductive success by Shively \& Smith (1985), based on social ranks, individuals with the highest or dominant social ranks recorded 7 adult males with 26 adult females with the potential for reproductive success to take place, through dyadic agonistic interactions. Because psychologically, individuals with high social ranks will try to maintain reproductive success throughout their life. According to Girard-Buttoz et al. (2014), psychologically alpha-male has a very high stressor for mating competition among other adult male individuals in the group. This psychological stressor affects adult female monopolization. This is known as reproductive suppression in primates (Dunbar, 1988).

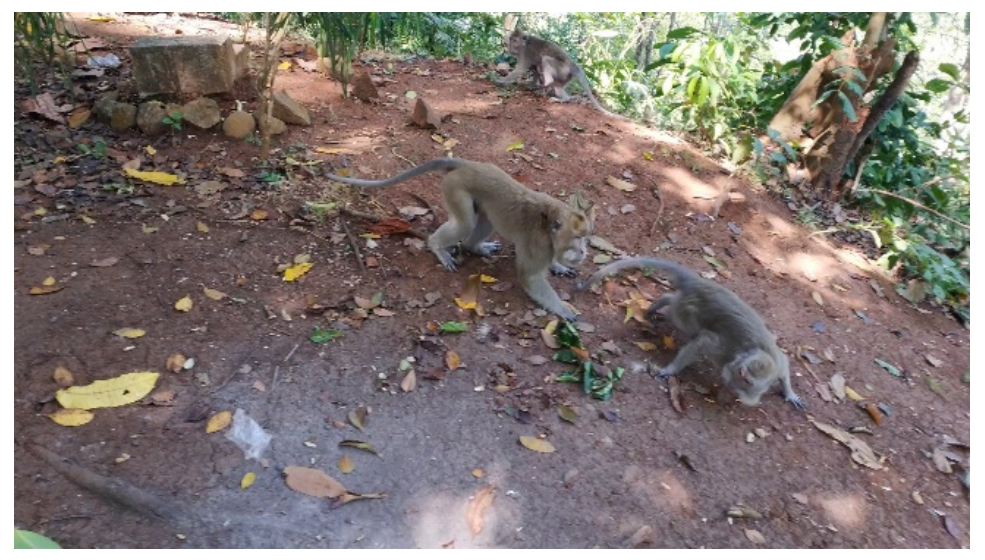

Figure 3. Alpha-male initiates conflict against Jim by chasing and issuing voice threats.

Males, physically and influenced by psychological stressors, can initiate fights as well as improve their psychological abilities. Whoever wins, mentally, the winner will succeed and succeed in that condition. This can cause the aggressive behavior of males to increased (Dunbar, 1988). During the 8-day observation, it was recorded that adult male showed the highest aggressive behavior, followed by alpha-male. Not infrequently, one of the aggressive actions is in the form of a fight and is initiated by individuals who are dominant in social ranks.

Infants were not recorded to be aggressive during the observation period. According to de Waal \& Ferrari (2012), the individual development of the child from birth tries to learn from the parental. Parental try to provide a good learning process, not including aggressive learning, the infant will be taught with "Do as I Do" during development towards adulthood.

\section{CONCLUSION AND RECOMMENDATION}

The aggressive behavior shown by adult males and alpha-male ranks the highest during the observation. This is due to the psychological stressors they get, to support reproductive success, control of resources, and antipredatory behavior.

This research is limited to the behavioral observation method, so it is necessary to conduct future research using hormonal and neuropsychological level indicators to obtain more accurate research results related to the psychological condition of Macaca fascicularis.

\section{Acknowledgments}

The authors have support to report of this study by acknowledged to Tegar Kusuma, Sri Budi Hastuti, Nadhilla Haura Wahyudiana, Muhammad Iqbal, Pandu Suryo Nugroho, and Siti Rukayah.

\section{Funding}

The authors have no funding to report.

\section{Competing Interest}

The authors declare that they have no competing interests.

\section{REFERENCES}

Al Hakim, R. R. (2021). Perbandingan Tingkah Laku Harian Alpha-male Monyet Ekor Panjang (Macaca fascicularis) dengan Jantan Lain Di TWR Makam Mbah Agung Karangbanar [Universitas Jenderal Soedirman]. https://doi.org/10.13140/RG.2.2.24569.19046

Altmann, J. (1974). Observational Study of Behavior: Sampling Methods. Behaviour, 49(3-4), 227-266. https://doi.org/10.1163/156853974X00534

Anderson, J. A., \& Kinnally, E. L. (2020). Behavioral mimicry predicts social favor in adolescent rhesus macaques (Macaca mulatta). Primates, 1-9. https://doi.org/10.1007/s10329-020-00861-y

Bardi, M., Prugh, A. M., Eubanks, B. T., Trexler, K., Bowden, R. L., Evans, S., Lambert, K. G., \& Huffman, M. A. (2017). Physiologic correlates of interactions between adult male and immature long-tailed macaques (Macaca fascicularis). Journal of the American Association for Laboratory Animal Science, 56(6), 718-728.

Coleman, K. (2012). Individual differences in temperament and behavioral management practices for nonhuman primates. Applied Animal Behaviour Science, 138(1-2), 106-113. https://doi.org/10.1016/j.applanim.2011.08.002

de Waal, F. B. M., \& Ferrari, P. F. (2012). The Primate Mind: Build to Connect with Other Minds. Harvard University Press. file:///C:/Users/youhe/Downloads/kdoc_o_00042_01.pdf 
Dunbar, R. I. M. (1988). Primate Social Systems. Croom Helm Australia. https://doi.org/10.1007/978-1-4684-6694-2

Freeman, H. D., \& Gosling, S. D. (2010). Personality in nonhuman primates: A review and evaluation of past research. American Journal of Primatology, 72(8), 653-671. https://doi.org/10.1002/ajp.20833

Girard-Buttoz, C., Heistermann, M., Rahmi, E., Agil, M., Ahmad Fauzan, P., \& Engelhardt, A. (2014). Costs of mate-guarding in wild male long-tailed macaques (Macaca fascicularis): Physiological stress and aggression. Hormones and Behavior, 66(4), 637-648. https://doi.org/10.1016/j.yhbeh.2014.09.003

Gygax, L. (2000). Hiding behaviour of long-tailed macaques (Macaca fascicularis): II. Use of hiding places during aggressive interactions. Ethology, 106(5), 441-451. https://doi.org/10.1046/j.1439-0310.2000.00549.x

Hansen, M. F., Gill, M., Nawangsari, V. A., Sanchez, K. L., Cheyne, S. M., Nijman, V., \& Fuentes, A. (2021). Conservation of Longtailed Macaques: Implications of the Updated IUCN Status and the CoVID-19 Pandemic. Primate Conservation, 35, 111.

Kappeler, P. M., \& Schaik, C. P. Van. (2006). Cooperation in Primates and Humans - Mechanisms and Evolution. Springer-Verlag.

Lutz, C. K., \& Brown, T. A. (2018). Porches as enrichment for singly housed cynomolgus macaques (Macaca fascicularis). Journal of the American Association for Laboratory Animal Science, 572), 134-137.

Maestripieri, D. (2003). Primate Psychology. Harvard University Press. https://www.mculture.go.th/mculture_th/download/king9/Glossary_about _HM_King_Bhumibol_Adulyadej's_Funeral.pdf

McCowan, B., Beisner, B. A., Capitanio, J. P., Jackson, M. E., Cameron, A. N., Seil, S., Atwill, E. R., \& Fushing, H. (2011). Network stability is a balancing act of personality, power, and conflict dynamics in rhesus macaque societies. PLoS ONE, 6(8). https://doi.org/10.1371/journal.pone.0022350

Mishra, P. S., Pal, A., Velankar, A. D., Kumara, H. N., \& Singh, M. (2020). Do males bond? A study of male-male relationships in Nicobar long-tailed macaques Macaca fascicularis umbrosus. Journal of Biosciences, 45(1). https://doi.org/10.1007/s12038-020-9995-y

Nasution, E. K., \& Rukayah, S. (2018). Daily Activities of Long Tail Monkeys ( Macaca fascicularis Raffles) in Cikakak Tourist Resort Wangon Banyumas (a Conservation Effort). The SEA+ Conference on Biodiversity and Biotechnology 2018, 1-5. https://doi.org/10.1088/1755-1315/593/1/012004

Nugroho, D. A. A., Sajuthi, D., Mansjoer, S. S., Iskandar, E., \& Darusman, H. S. (2021). Model psikologi komparatif ketidaksetaraan jumlah pembagian sumber daya: Studi pada Macaca fascicularis. Jurnal Psikologi Sosial, 19(1), 725. https://doi.org/10.7454/jps.2021.03

Robinson, L. M., Waran, N. K., Handel, I., \& Leach, M. C. (2021). Happiness, welfare, and personality in rhesus macaques (Macaca mulatta). Applied Animal Behaviour Science, 236(February), https://doi.org/10.1016/j.applanim.2021.105268

Setchell, J. M., \& Curtis, D. J. (2011). Field and Laboratory Methods in Primatology: A Practical Guide. In Cambridge University Press (2nd Editio). Cambridge University Press. https://www.mculture.go.th/mculture_th/download/king9/Glossary_about _HM_King_Bhumibol_Adulyadej's_Funeral.pdf

Shively, C., \& Smith, D. G. (1985). Social status and reproductive success of male Macaca fascicularis. American Journal of Primatology, $9(2)$ https://doi.org/10.1002/ajp.1350090206
Simpson, M. J. A., \& Simpson, A. E. (1977). One-zero and scan methods for sampling behaviour. Animal Behaviour, 25(3), 726-731. https://doi.org/10.1016/0003-3472(77)90122-1

Sterling, E. J., Bynum, N., \& Blair, M. E. (2013). Primate Ecology and Conservation: A Handbook of Techniques. Oxford University Press. https://doi.org/10.1093/acprof:oso/9780199659449.001.00 01

Veenema, H. C., Spruijt, B. M., Gispen, W. H., \& Van Hooff, J. A. R. A. M. (1997). Aging, dominance history, and social behavior in Java-monkeys (Macaca fascicularis). Neurobiology of Aging, 18(5), 509-515. https://doi.org/10.1016/S01974580(97)00107-3

Weiss, A., King, J. E., \& Murray, L. (2011). Personality \& Temperament in Nonhuman Primates. 